\title{
Editorial
}

\section{The health and fulure}

\section{of academic neurology}

\section{Alastair Compston}

University of Cambridge Neurology unit,

Addenbrooke's Hospital, Hills Road, Cambridge, UK;

Email: dascompston@aol.com

Practical Neurology 2002, 2, 66-67

Nobody much cared when theD odo (didusineptus) disappeared in 1681; after all, it wasn't much of a bird, being unable to fly despite having wings. Perhaps the Dodo is a poor metaphor for academic neurology: at a pinch, most professors can elicit the ankle jerks; and neurology boasts some awesomely talented investigators working internationally and producing research of lastingsignificanceacrossarangeof neurosciencedisciplines. But that said, all is not well - in the United Kingdom and elsewhere. Academic - adjective not noun - encapsulates the ethic of exploring problemsidentified by clinical analysis, intellectually and experimentally, and re-cycling theevidenceso as better to inform clinical practice. Thusdefined, every neurologist isacademic and, far from representing the transiently regrettable amputation of oneredundant branch, any threat to academic neurology endangers the entire species homo neurologiensis.

Despite real dividends from theexponential increase in neuroscience activity over the last decade, and unprecedented cultural interest in the brain, clinical application of that knowledge has made slow progress. Of course, applying the technical wizardry and opportunities for experimental manipulation in science to the problems of clinical neurology is not a trivial task. So, if basic neuroscience is strong, neurology is doing fine and yet clinical neuroscienceis under the cosh; what has gone wrong? The finger can bepointed atuniversities, fundingagenciesand reformers, but remediescan beproposed for thepresentlesionsand, with prevention rather than reconstruction, theprognosis should be good.

In the United Kingdom, medicine flourished and academic disciplines developed for nearly 40 years from inception of the National Health Service in 1948. Professionalism was the oil that made the medical engine work to deliver high quality care and 
advance knowledge despite under-resourcing. But, by the late 1980 s, with too much on offer and high expectationsfrom society, serial administrative re-organizations, disguised as long overdue reforms, were introduced to contain expenditure. Resistance to change was managed by distancing doctors from patients and creating smoke screens that confused quality with performance indicators, but (predictably) the real costs of service provision, teaching and research were exposed. $M$ anpower in academic neurology nevertheless increased into the late 1990s so as to supplement the provision of clinical servicesand teaching, reward career aspirations, and stabilisefaculties as deans sought to represent the major discipline of neurology - offering rich research pickings in each medical school. These academic appointees now find themselves exposed in a contracting research economy, and specifically disadvantaged as clinical neuroscientists. Systems for funding are seen to favour the elite and to inhibit the beginner. The alternative to starvation is to take big Pharma's shilling and piggy-back research onto clinical trials. With no apparent long-term strategy for supporting clinical neuroscience, the trend is to concentrate academic activities in fewer locations - the topics determined by short-term needs and opportunities rather than strategic investment in a portfolio subtending the entire needs of clinical neuroscience. The cynical $M$ artian could beforgiven for concluding that academic neurologists now either take photographs of the brain whilst their friends perform party tricks, or fish for genes without much clue on how to sort the catch. Performance and productivity areover-scrutinised. Faced with periodic inspection of therootsin order to assessgrowth, and no apparent consistency in research policy as new executive brooms sweep clean, moral eis low. Recruitment is reduced and yet it takes no very great wisdom to see that the future depends on the sustained transfer of enthusiasm and method to a new generation, giving them thetechnical expertise and motivation to keep neurology academic. Lose the culture, and thepracticedisappears. Nurture recruits, securetheir sustained commitment for subsequent transfer and continuity of the discipline, and all should bewell.

Once upon atime, exposureto the range of medical disciplines as students or junior residents allowed young doctors to chose their speciality and integrate clinical and research training rotations. They moved between people, places and projects subject to opportunity and ability. The house-keeping of those who governed neurology was tight. Thesystem was generally supportive and with few casualties. But junior residents are now largely denied this period of apprenticeship as an integral member of a medical firm. Those who do decideon a career in neurology must enter viaresearch and with no guarantee of aclinical trainingposition thereafter. Thesituation is especially difficult for the M B PhD student who has to mark timewhilst waiting for a clinical training post. Thereare tensions between N H S and university staff - afew professorial barons being seen as dominating recruitment and persistently down-loading their selections on N H S departments.

At present, thetwo major medical funding agencies in theUnited Kingdom (M edical Research Council and theWellcome Trust) processclinical applicationsthrough their neuroscienceand men- tal health panels. Clinical grants do badly becausetoo often they are methodologically over-ambitiousand perceived by scientific assessors to be flawed. Clinicians conclude that the licence to practice science is being withheld. Granting agencies seem more tolerant of the often unsubstantiated catch-all signature of practically all basic scientific proposals, '... from which new treatments will follow'. In failing to finesse the limitations of working with patients, criticism isalso often levelled by clinical peer reviewers- dog routinely eating dog. It is rarely possible to justify clinical salaries for staff supported on neuroscienceprojectsunlessthework requiresdirect contact with patients and yet the pressure on personal basic medical sciencefellowships is intense. When last surveyed (2000), 30 of 324 (9\%) M RC and Wellcomeclinical fellowships (basic, advanced or clinician scientist) were awarded to clinical neurologists, 19 of which were located in just two institutions. Disappointed applicants often sensethat they havebeen assessed for 'an al ready trained in science' fellowship rather than a'clinical training' fellowship.

In short, academic neurology is now in a post-expansionist era with patchy inter-unit performance, activity restricted to a narrow range of topics, an insufficient science base for clinically-orientated research, growing dependence on conditional pharmaceutical support, restricted entry atjunior resident grade, poor post-research neurology trainee entry career paths, lack of flexible training schemes, and difficulty in maintaining research activity during the formative years as an independent investigator. Three adjustments would help.

First, existing activities within universities need to be re grouped to createinterdisciplinary teamswith both scientific and clinical expertise, combining theexperimental rigour of basicsciencewith the critical analyses of clinical neurology to the mutual benefit of each. Second, themajor research fundingorganizations need to prioritizesupport for clinical neuroscience. I tmay benecessary to separate funding from the basic science portfolio with assessment by a panel experienced in clinical science, but without creating a soft and hencesecond class culture- real or perceived. Third, a training infrastructure is needed that enhances recruitment, establishes individuals as independent investigators, and graduates trainees as trainers to pass on the research mantle. At present, themovebetween research and clinical training isabrupt and transitional success not secure. Faced with uncertainty at entry, exit and re-entry into research, potential career clinician neuroscientistsmay opt away from an academic appointment or even chose a better-managed speciality. To make the academic track more attractive, research fellowships should be linked to clinical training with a flexible curriculum and postdoctoral opportunities; increasing the number of postdoctoral advanced training, clinician scientist and senior fellowships, linked to clinical and senior lectureships in the University sector, would allow a cohort of committed neurologists to maintain research activity and credibility through to tenured appointment.

If academic neurology is not to go theway of the Dodo, tweaking the system now makes better sense than ignoring the distress signals and leaving an ostrich-likehead in thesand (somewhat to mix the metaphor). 